\title{
Cost of Non-Respiratory Drugs in Copd
}

\author{
Alida Sina \\ PhD Student, Health Insurance Institute, Tirana, Albania \\ E-mail: alida_sina@yahoo.com

\section{Zamira Shabani} \\ University of Shkoder "Luigj Gurakuqi", Sheshi "2 Prilli", Shkodër - Albania \\ E-mail: shabanizamira@yahoo.com
}

\section{Doi:10.5901/ajis.2013.v2n8p82}

\section{Abstract}

Poly-therapy is often prescribed for the treatment of Chronic Obstructive Pulmonary Disease (COPD) patients. The numerous drugs are needed to treat COPD and also its comorbidities. Medicines needed to treat comorbid conditions add to the daily cost of COPD care. This study evaluates the costs of all reimbursed drugs used from Albanian outpatients with COPD over a year, in order to highlight the impact of non-respiratory drugs. Methods The data on costs of all reimbursed drugs used in 2012 from insured COPD outpatients were obtained from Health Insurance Institute database. Drugs and their costs were divided according to the first level (main anatomical group) and the second level (main therapeutic group) of International Anatomical Therapeutic Chemical (ATC) classification system. All the data are calculated with Microsoft Office Excel program. Results In 2012 non-respiratory drugs represented 45\% of total drug reimbursement for Albanian outpatients with COPD. More expensive drugs were the ones acting on: Cardiovascular system (57\% of non-respiratory drug reimbursement), Alimentary tract and metabolism (16\%), Sensory organs (7\%), Genito - urinary system and sexual hormones (6\%) and Nervous system (5\%). It was found no correlation between the number of COPD outpatients and non-respiratory drug reimbursement. Non-respiratory drugs used in insured COPD outpatients are associated with considerable cost and they should be considered when estimating economic burden of COPD. Drugs acting in cardiovascular system and those used in diabetes have the most increased cost among them.

Keywords: ATC classification, COPD, cost, drugs.

\section{Introduction}

Most Chronic Obstructive Pulmonary Disease (COPD) patients suffer from other chronic medical conditions as well. 1,2 These conditions that are common at any severity of $\mathrm{COPD}^{3}$ are called comorbidities. Frequent comorbidities of patients with COPD include arthritis, cardiac disorders, hypertension, diabetes mellitus, lipid disorders, psychiatric conditions, gastrointestinal diseases, cancer, and osteoporosis (Table 1). Although it is widely accepted that COPD is associated with certain comorbidities the precise prevalence varies largely among epidemiological studies. ${ }^{2}$

Table 1. Chronic Obstructive Pulmonary Disease and the prevalence of common comorbidities (\%)

\begin{tabular}{|l|c|c|c|c|c|c|c|c|c|c|}
\hline Source & $\mathbf{n}$ & Arthritis & Cardiac & HTN & Diabetes & Lipids & Psych & GI & Cancer & Osteoporosis \\
\hline $\begin{array}{l}\text { van Manen and } \\
\text { colleagues (4) }\end{array}$ & 1,145 & 36 & 13 & 23 & 5 & - & 9 & 15 & 6 & - \\
\hline $\begin{array}{l}\text { Mapel and } \\
\text { colleagues (5) }\end{array}$ & 200 & 22 & 65 & 45 & 12 & - & 17 & 32 & 18 & - \\
\hline $\begin{array}{l}\text { Soriano and } \\
\text { colleagues (6) }\end{array}$ & 2,699 & 28 & 22 & - & - & - & 10 & 26 & 4 & - \\
\hline $\begin{array}{l}\text { Sidney and } \\
\text { colleagues (7) }\end{array}$ & 45,97 & - & 18 & 18 & 2 & 9 & - & - & - & - \\
\hline $\begin{array}{l}\text { Walsh and } \\
\text { Thomashow (8) }\end{array}$ & 3 & 70 & 50 & 52 & 16 & 51 & 38 & 62 & 4 & 32 \\
\hline
\end{tabular}

Definition of abbreviations: - = no available data; $\mathrm{GI}$ = gastrointestinal disturbances; $\mathrm{HTN}=$ hypertension 
Unfortunately, the presence of both COPD and other comorbidities is often ominous and contributes significantly to poor health outcomes. ${ }^{9,10}$ In fact, numerous studies have suggested that comorbidities are a common cause of or contributor to COPD hospitalizations. ${ }^{11}$ In a study of over 45.000 patients with COPD, heart failure was the leading cause of hospitalization, followed by myocardial infarction and stroke. ${ }^{7}$ Kinnunen and colleagues found that comorbidities were associated with an increased duration of COPD hospitalizations; the mean length-of-stay in patients without comorbidity was 7.7 days compared with 10.5 days if a concurrent disease was present. ${ }^{12}$ So these comorbid conditions not only cause hospitalization, but also influence the length of hospital stay of patients with COPD.

Furthermore, some studies evaluating the cause of death in COPD suggest that patients with COPD are more likely to die of comorbid conditions rather than COPD, with most deaths from cardiovascular disease or malignancy (Table 2), although this varies with the severity of COPD.

Table 2. Reported causes of mortality in patients with Chronic Obstructive Pulmonary Disease (\%)

\begin{tabular}{|l|c|c|c|c|c|c|}
\hline Author & Site & $\begin{array}{c}\text { Patients with } \\
\text { COPD Dying }\end{array}$ & $\begin{array}{c}\text { Cause: } \\
\text { COPD (\%) }\end{array}$ & $\begin{array}{c}\text { Cause: } \\
\text { Cardiovascular (\%) }\end{array}$ & $\begin{array}{c}\text { Cause: } \\
\text { Malignancy (\%) }\end{array}$ & $\begin{array}{c}\text { Cause: Other } \\
\text { Respiratory (\%) }\end{array}$ \\
\hline Camilli and colleagues (13) & Tucson & 86 & 23 & 42 & 9 & 26 \\
\hline Huiart and colleagues (14) & Canada & 2.000 & 14 & 38 & & \\
\hline Anthonisen and colleagues (15) & $\begin{array}{c}\text { United } \\
\text { States }\end{array}$ & 149 & $<15$ & 25 & 60 & \\
\hline Keistinen and colleagues (16) & Europe & 973 & 22 & 37 & 21 & 4 \\
\hline Vilkman and colleagues (17) & Europe & 1.070 & 30 & 37 & 20 & \\
\hline
\end{tabular}

Therefore, comorbidities should be looked for routinely, and treated appropriately, in any patient with COPD ${ }^{1}$, as they contribute to impared clinical course and poor prognosis of COPD patients. COPD patients in general take a large number of drugs. Polypharmacy that characterizes these patients consists of respiratory drugs, especially inhaled ones needed for COPD treatment, and non-respiratory drugs used for the treatment of multiple extra-pulmonary conditions that accompany COPD.

Insured Albanian outpatients with COPD also are treated with numerous non-respiratory drugs. These medicines add to the daily-cost of COPD care. As the costs of reimbursed drugs are affordable totally or partially by the Health Insurance Institute, this study evaluates the costs of all drugs used from Albanian insured outpatients with COPD over a year and highlights the impact of non-respiratory drugs.

\section{Materials and Methods}

This retrospective study was conducted using Albanian Health Insurance Institute database. This institute was unique in Albania as a single-payer and involved all insured population. Its database contained data recorded from reimbursed medical prescriptions. The diagnosis codes, according to the International Classification of Diseases, Ninth Revision (ICD-9), insured outpatient codes, drug codes and drug costs were some important data of the reimbursed prescriptions which were recorded in every case in the Health Insurance Institute database. Drug code was created by Health Insurance Institute and it was associated with specific Anatomical Therapeutic Chemical (ATC) drug code in the database. The costs of reimbursed drugs were initially calculated by pharmacists based on the prices of reimbursed drug list published by Health Insurance Institute. All costs were expressed in Albanian currency (Lek). The costs paid by outpatients' pocket for drugs which were partially reimbursed by Health Insurance Institute were not included in this study because of their little influence.

First of all, insured COPD outpatients were identified using ICD-9 codes. Information about reimbursement of all drugs used from these outpatients in 2012 was then analyzed using international ATC system classification.

This classification divides the drugs in groups at five different levels according to the organ or system on which they act and according to their chemical, pharmacological and therapeutic properties. ${ }^{18,19}$

All reimbursed drugs and their costs were divided according to the first level (main anatomical group) and the second level (main therapeutic group) of ATC classification and the results were expressed as percentage of total costs. It was used Microsoft Office Excel Program for all calculations.

Furthermore, Pearson correlation coefficient was computed and a significance test was conducted to found out whether the number of insured COPD outpatients and the costs of non-respiratory drugs used from them were correlated. 


\section{Results}

Total cost of respiratory and non-respiratory drugs reimbursed for Albanian outpatients with COPD was approximately $224 \mathrm{mln}$ Lek in 2012. $124 \mathrm{mln}$ Lek (55\%) were expended for respiratory drugs and $100 \mathrm{mln}$ (45\%) was the reimbursement of non-respiratory drugs used in the same outpatients for the treatment of comorbidities (Figure 1).

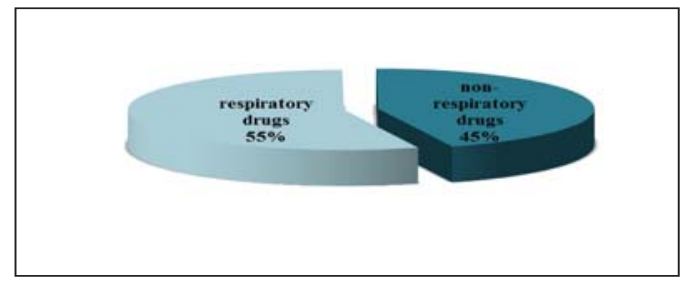

Figure 1. Costs (\%) of respiratory and non-respiratory drugs used from Albanian insured outpatients with COPD in 2012

Among non-respiratory drugs higher costs were for the ones acting on: Cardiovascular system with $\mathrm{C}$ code ( $57 \%$ of nonrespiratory drug cost), Alimentary tract and metabolism with A code (16\%), Sensory organs with S code (7\%), Genito urinary system and sex hormones with $\mathrm{G}$ code (6\%) and Nervous system with $\mathrm{N}$ code (5\%) (Figure 2).

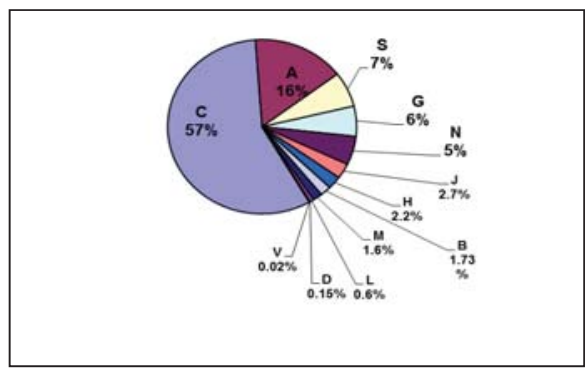

Figure 2. Costs (\%) of reimbursed non-respiratory drugs used in ambulatory COPD in 2012 according to ATC anatomical groups

Drugs belonged to $\mathrm{C09}$ and C08 therapeutic groups according to ATC classification had higher costs among cardiovascular ones (Table 3).

Table 3. Costs (\%) of reimbursed cardiovascular drugs used in COPD in primary care in 2012 according to ATC therapeutic groups

\begin{tabular}{|l|c|}
\hline Therapeutic groups & Annual Costs (\%) \\
\hline C01 - Cardiac Therapy & 8 \\
\hline C02 - Antihypertensives & 4 \\
\hline C03 - Diuretics & 9,5 \\
\hline C07 - Beta Blocking Agents & 10,5 \\
\hline C08 - Calcium Channel Blockers & 25 \\
\hline C09 - Agents Acting on the Renin-Angiotensin System & 38 \\
\hline C10 - Lipid Modifying Agents & 5 \\
\hline
\end{tabular}

$80 \%$ of total cost of reimbursed medications acting on alimentatry tract and metabolism belonged to antidiabetics with ATC code A10.(Figure 3). 


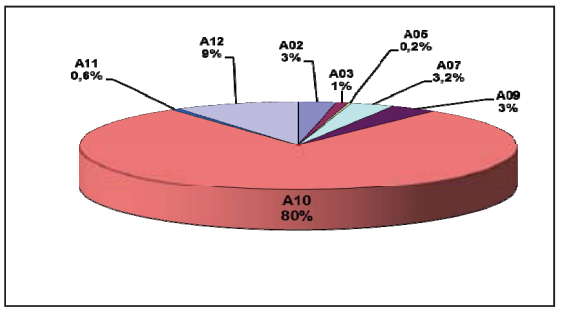

Figure 3. Costs (\%) of reimbursed drugs acting on alimentary tract and metabolism and used in COPD in primary care in 2012 according to ATC therapeutic groups

Only ophthalmologicals were used for the treatment of sensory organs diseases associated with COPD. Costs of alfuzosine, tamsulosine, terazosine and finasteride drugs reimbursed for the treatment of benign prostatic hypertrophy represented $70 \%$ of annual cost of drugs acting on genito urinary system and sex hormones prescribed in COPD outpatients in 2012 (Table 4).

Table 4. Costs (\%) of reimbused drugs acting on genito urinary system and sex hormones used in COPD in primary care in 2012 according to ATC therapeutic groups

\begin{tabular}{|l|c|}
\hline Therapeutic groups & Annual Costs (\%) \\
\hline G01 - Gynecological Antiinfectives and Antiseptics & 1 \\
\hline G03 - Sex Hormones and Modulators of the Genital System & 28 \\
\hline G04 - Urologicals & 71 \\
\hline G04B - Other urologicals, incl. antispasmodics & 1 \\
\hline G04C - Drugs used in benign prostatic hypertrophy & 70 \\
\hline
\end{tabular}

Among drugs acting on the nervous system, most costly were the ones classified in N05A therapeutic subgroupantipsychotics. Antiparkinson and antiepileptic drugs also had high reimbursed costs, whereas all psychoanaleptics used in COPD were antidepressants (Table 5).

Table 5. Costs (\%) of reimbused drugs acting on nervous sytem used in COPD in primary care in 2012 according to ATC therapeutic groups

\begin{tabular}{|l|c|}
\hline Therapeutic group & Annual Costs (\%) \\
\hline N02 - Analgesics & 11 \\
\hline N03 - Antiepileptics & 15 \\
\hline N04 - Antiparkinson Drugs & 26 \\
\hline N05 - Psycholeptics & 41 \\
\hline N05A - Antipsychotics & 36 \\
\hline N05B - Anxiolytics & 5 \\
\hline $\begin{array}{l}\text { N06 - Psychoanaleptics } \\
\text { (N06A - Antidepressants) }\end{array}$ & 7 \\
\hline
\end{tabular}

There was no significant correlation between the number of COPD outpatients and the reimbursement cost of nonrespiratory drugs used for the treatment of COPD comorbidities.

\section{Discussion}

Albanian insured outpatients with COPD were exposed to many different non-respiratory drugs showing the presence of other coexisting conditions in the same patients. As a result, non-respiratory drugs had a considerable cost with $45 \%$ of the total drug cost reimbursed for COPD outpatients in 2012. In fact, concomitant comorbidites among COPD patients are associated with elevated healthcare costs. ${ }^{20,21}$ Medications used for the treatment of such comorbidities are only one of the components contributing to these elevated costs. 
More than half of non-respiratory drug reimbursement was paid for cardiovascular drugs. Several studies suggest that cardiovascular diseases (CVD) are more frequent in COPD patients than in general population and may represent a burden greater than that of lung disease itself (Burney et al 2003; Holguin et al 2005; Huiart et al 2005). ${ }^{22}$ Cardiovascular co-morbidity existed in 13\% - 65\% of COPD subjects in different studies (Table 1) and is probably the main comorbidity in COPD (Fabbri et al, 2008; Soriano et al, 2005).

On the other hand, antidiabetics represented $80 \%$ of the cost of drugs acting on alimentary tract and metabolism, because diabetes mellitus frequently is associated with COPD. Large population studies show that there is an increased prevalence of diabetes among COPD patients (relative risk 1.5-1.8), even in patients with mild disease. ${ }^{23,24}$

Glaucoma, prostate cancer, Parkinson's disease and mental disorders especially depression and anxiety are also other reported comorbidities of patients with COPD. This explains the significant costs of ophtalmologicals, drugs used in benign prostatic hypertrophy and drugs acting on the nervous system as medications used for the treatment of such comorbidities.

Mood disorders, including depression and anxiety, are more prevalent in patients with COPD than in the general population. ${ }^{25}$ However, anxiety and depressive disorders are underrecognized $(<40 \%)$ and undertreated (approximately $30 \%$ ) in patients with COPD. ${ }^{26}$

So the results about most costly non-respiratory drugs used in insured COPD outpatients in Albania, in general are in agreement with findings of numerous studies regarding the patterns of non-pulmonary comorbidities in COPD and the drugs used for their treatment.

Studies often are focused only on the impact of drugs used for the main disease which is COPD in this case. In this context, the costs evaluation of reimbursed drugs used for treating associated conditions of COPD becomes important, as these costs have not been before the object of any study in Albania.

There appear to be a number of mechanisms by which co-morbid conditions arise in patients with COPD other than by chance. The first of these is sharing of common risk factors. These include poor socioeconomic status, smoking and age which are clearly risk factor for a large range of conditions. Another mechanism is the increasingly well described systemic effects of COPD (Fabbri and Rabe 2007). This systemic inflammation is now thought to impact on extrapulmonary organs such the heart and blood vessels as well as the metabolic system. In addition, the effects of COPD increases the risks of other conditions with breathlessness, inactivity, and exacerbations resulting in depression, anxiety, and inactivity with resulting osteoporosis risk ad muscle loss. Finally, COPD treatment may in itself increase the risk of other conditions particularly those related to oral steroid usage. ${ }^{27}$

The absence of correlation between the number of COPD outpatients and costs of non-respiratory drugs used from them may be explained by the fact that prevalence of comorbidities varies considerably in different populations with COPD.

At last, it should be taken in consideration that only reimbursed drugs have been the object of this study. So it can be supposed that the impact of all non-respiratory drugs, reimbursed and non-reimbursed, and which are prescribed for all COPD outpatients, with and without health insurance, could be a little bit different from the results of this study. Moreover, relating to the limited healthcare resources, cost-effective therapies should be prescribed for COPD and its comorbidities as well. This suggestion is especially valuable for the care management of COPD patients with specific and frequent comorbidities treated with most costly drugs.

\section{Conclusion}

Reimbursed non-respiratory drugs are frequently used for the treatment of COPD comorbidities in primary care and their economic impact is considerable. Cardiovascular drugs and those used in diabetes mellitus have the most increased cost. As a result, not only respiratory drugs used for the treatment of COPD as the main disease, but also non-respiratory drugs used for the treatment of COPD extra-pulmonary comorbidities should be considered when evaluating the economic burden of COPD. Moreover, considering the limited health care resources it is important to use cost-effective therapies not only for COPD, but also for the treatment of its different comorbidities. This suggestion is especially valuable for care management of COPD patients with specific and frequent comorbidities treated with most costly drugs.

\section{References}

Global Initiative for Chronic Obstructive Lung Disease (GOLD). Global Strategy for Diagnosis, Management, and Prevention of Chronic Obstructive Pulmonary Disease. (Revised 2011). Available at: http://www.goldcopd.org Accessed online May 05, 2013

Chatila WM, Thomashow BM, Minai OA, et al. Comorbidities in chronic obstructive pulmonary disease. Proc Am Thorac Soc 2008; 5 : 
549-555.

Agusti A, Calverley PM, Celli B, et al. Characterisation of COPD heterogeneity in the ECLIPSE cohort. Respir Res 2010; 11: 122

van Manen JG, Bindels PJ, IJzermans CJ., van der Zee JS, Bottema BJ, Schade E. Prevalence of comorbidity in patients with a chronic airway obstruction and controls over the age of 40. J Clin Epidemiol 2001; 54: 287-293.

Mapel DW, Hurley JS, Frost FJ, Petersen HV, Picchi MA, Coultas DB. Health care utilization in chronic obstructive pulmonary disease: a case-control study in a health maintenance organization. Arch Intern Med 2000; 160:2653-2658.

Soriano JB, Visick GT, Muellerova H, Payvandi N, Hansell AL. Patterns of comorbidities in newly diagnosed COPD and asthma in primary care. Chest 2005; 128:2099-2107.

Sidney S, Sorel M, Quesenberry CP Jr, DeLuise C, Lanes S, Eisner MD. COPD and incident cardiovascular disease hospitalizations and mortality: Kaiser Permanente Medical Care Program. Chest 2005; 128: 2068-2075.

Walsh JW, Thomashow BM. COPD and co-morbidities: results of COPD Foundation national survey. Paper presented at: COPD and comorbidities: treating the whole patient. ATS 2006 San Diego International Conference; 2006 May 19-24; San Diego, CA.

Holguin F, Folch E, Redd SC, Mannino DM. Comorbidity and mortality in COPD-related hospitalizations in the United States, 1979 to 2001. Chest 2005; 128:2005-2011

Antonelli Incalzi R, Fuso L, De Rosa M, Forastiere F, Rapiti E, Nardecchia B, Pistelli R. Co-morbidity contributes to predict mortality of patients with chronic obstructive pulmonary disease. Eur Respir J 1997; 10: 2794-2800.

Fabbri LM, Luppi F, Beghe B, Rabe KF. Complex chronic comorbidities of COPD. Eur Respir J. 2008; 31: 204-212.

Kinnunen T, Saynajakangas O, Tuuponen T, Keistinen T. Impact of comorbidities on the duration of COPD patients' hospital episodes. Respir Med 2003; 97:143-146.

Camilli AE, Robbins DR, Lebowitz MD. Death certificate reporting of confirmed airways obstructive disease. Am J Epidemiol 1991; 133: 795-800.

Huiart L, Ernst P, Suissa S. Cardiovascular morbidity and mortality in COPD. Chest 2005; 128: 2640-2646.

Anthonisen NR, Connett JE, Enright PL, Manfreda J, Lung Health Study Research Group. Hospitalizations and mortality in the Lung Health Study. Am J Respir Crit Care Med 2002; 166: 333-339.

Keistinen T, Tuuponen T, Kivela SL. Survival experience of the population needing hospital treatment for asthma or COPD at age 50-54 years. Respir Med 1998; 92:568-572.

Vilkman S, Keistinen T, Tuuponen T, Kivela SL. Survival and cause of death among elderly chronic obstructive pulmonary disease patients after first admission to hospital. Respiration 1997; 64:281-284.

WHO Collaborating Centre for Drug Statistics Methodology, Guidelines for ATC classification and DDD assignment 2012. Oslo, 2011.website: www.whocc.no

Introduction to drug utilization research / WHO International Working Group for Drug Statistics Methodology, WHO Collaborating Centre for Drug Statistics Methodology, WHO Collaborating Centre for Drug Utilization Research and Clinical Pharmacological Services. WHO 2003

Gerdtham UG, Andersson LF, Ericsson A, Borg S, Jansson SA, Ronmark E, Lundback B: Factors affecting chronic obstructive pulmonary disease (COPD) - related costs: a multivariate analysis of a Swedish COPD cohort. Eur J Health Econ 2009, 10(2):217-226

Lin PJ, Shaya FT, Scharf SM:Economic implications of comorbid conditions among Medicaid beneficiaries with COPD. Respir Med 2010, 104(5):697-704.

Anecchino C, Rossi E, Fanizza C, et al. Prevalence of chronic pulmonary disease and pattern of comorbidities in a general population. Int J COPD 2007; 2(4): 567-574.

Mannino DM, Thorn D, Swensen A, Holguin F. Prevalence and outcomes of diabetes, hypertension, and cardiovascular disease in chronic obstructive pulmonary disease. Eur Respir J 2008; 32: 962-969.

Rana JS, Mittleman MA, Sheikh J, et al. Chronic obstructive pulmonary disease, asthma, and risk of type 2 diabetes in women. Diabetes Care 2004;27:2478-2484.

Kao CC, Hanania NA. Co-morbidities of COPD: systematic inflammation. In: Crapo J, ed. Atlas of Chronic Obstructive Pulmonary Disease. Philadelphia, PA: Current Medecine Group; 2009: 169-177

Kunik ME, Roundy K, Veazey $\mathrm{C}$, et al. Surprisingly high prevalence of anxiety and depression in chronic breathing disorders. Chest 2005; 127: 1205-1211

Crockett AJ and Price D. Co-morbid disease in COPD-more than a coincidence. Int J Chron Obstruct Pulmon Dis 2007; 2(4): 399-401. 